\title{
Digital technologies in the agricultural sector of the Russian Federation
}

\author{
Elena Ogorodnikova ${ }^{1}$, Galina Zaloznaya ${ }^{1}$, Juliana Singaeva, Andrey Bart ${ }^{1}$, and Elena \\ Dmitrieva $^{2}$ \\ ${ }^{1}$ Orenburg State Agricultural University, 63, Leninskaya str., 460014, Orenburg, Russia \\ ${ }^{2}$ Orenburg State University, 13, Pobeda avenue, 460018, Orenburg, Russia
}

\begin{abstract}
The modern directions of the implementation, application and use of modern digital technologies in the agricultural sector are reviewed and evaluated. The implementation of the Digital AIC platform will create a new model of economic behavior of agricultural producers and give them additional income, many times exceeding all state support for the AIC. A methodology for the analysis and synthesis of the implementation of digital technologies in the Russian agro-industrial complex has been formed in the article, which will allow to determine the laws and factors of the formation of problems of the implementation of digital technologies in the agroindustrial complex, to study trends in the dynamics of digital technologies in order to identify promising areas for expanding the implementation of digital technologies. As a result of application of the methods of analysis and synthesis (literature analysis, analysis of modern documents, analysis of the results of the introduction of digital technologies), the causes and factors "inhibiting" the introduction of digital technologies in Russia are identified, trends and factors affecting the growth (decrease) rate of the introduction of digital technologies are identified in Russia.
\end{abstract}

\section{Introduction}

At the beginning of the XXI century, large agricultural holdings began to appear in Russia. In the mid-2010s, agricultural producers got the right and real potential to invest in digital modern technologies. It was for this reason soil, weather, and plant condition sensors appeared on the fields, and agronomists got the opportunity to use applications that aggregated a complete set of indicators from the fields. According to the Internet Initiatives Development Fund (IIDF) "roadmap" for the introduction of high technology in agriculture, it was assumed that in 2019 one third of Russian households will be able to use the Internet of things, advanced digital technologies and big data in their work [1].

At different times, such foreign scientists and researchers as Bukh R., Heeks R, Peter V.V. Philips, Zhesika L., John M. and others made a significant contribution to the development of the digital technologies theory in the agricultural sector.

As the subject of research by Russian scientists, the digital technologies in the agriculture have become relatively recent. Among studies of this kind, it is worth

\footnotetext{
* Corresponding author: lena-dozent@mail.ru
} 
highlighting the works by Vartanova M.L., Aleksandrova L.A. and others. It was the works by these authors that served as the methodological aspects of the implementation of this study.

The stated points determine the relevance of the research topic, as well as its purpose and objectives.

The purpose of the study is to develop a methodology for a comprehensive analysis of the state and process of implementation digital technologies in the Russian agricultural sector, which will allow us to study the patterns and factors affecting the effective implementation of digital technologies in the country.

In accordance with this goal the following tasks were set and solved:

1. The theoretical foundations of the digital technologies introduction in the economy were studied;

2. The analysis of priority areas for the implementation of digital technologies in Russia;

3. Digital products for the agricultural sector were considered;

4. The factors that have the greatest impact on the introduction of digital products for the agricultural sector have been identified.

The subject of the study is economic relations that are formed in the process of introducing digital technologies in the agricultural sector.

The object of the research is digital technology in the agricultural sector.

\section{Theory}

The topic of research on the digital technologies introduction in the agricultural sector is being actively studied, but, despite this, it requires constant analysis and development of recommendations for managing this process at different stages of the country's development.

Most of the studied works of domestic and foreign researchers are related to the following aspects of the topic:

- determination of the most effective methods for introducing digital technologies in agriculture based on a synthesis of theoretical and practical experience in solving this problem [1];

- study of the causes and dynamics of the implementation of the President of the Russian Federation Decree of the on state goals and strategic objectives of the Russian Federation for the period up to 2024 and methods for its effective implementation [2];

- development of a mechanism for digital transformation of the Russian economy [3];

- development of rural digital diversification technologies and the well-being of Nepal's households [4], etc.

\section{Data and Methods}

The authors used such methods as analysis, statistical research, comparison and contrasts when studying the process of the current state of the introduction of digital technologies in the agricultural sector of Russia.

This study will make possible to determine the patterns and factors of the introduction of digital technologies in the agricultural sector, the priority areas for the introduction of digital technologies, as well as to study their impact on macroeconomic processes in the agricultural sector. 


\section{Results}

In modern Russia, the digitalization of the agricultural sector has already become a priority project at the national level. In the meantime, the introduction of advanced digital technologies is being hampered by a lack of funding and qualified personnel.

The active use of modern digital technologies by the Russian agro-industrial complex was approved at the Government level as part of the Digital Agriculture Project, which provides the development of this segment until 2024. Many technologies are already used in the Russian regions. But the percentage of penetration of "smart" farming and animal husbandry today remains small and first of all it concerns peasant farms [2].

In the modern Russian economy the introduction of advanced digital technologies in the agricultural sector has three priority directions:

- systematic use of resources;

- introduction of digital technology;

- introduction of digital agricultural management.

Digital technologies help agro-producers to lead to optimal volumes of resources, to obtain a higher volume of production at minimal costs. Agriculture is the fourth sector of the economy in terms of the potential for introduction digital modern technologies, which is high enough compared to such sectors as construction, insurance and trade. Implementation of only farm management software in the near future will reach $\$ 1.6$ billion. Thereby financial investments from digital IT companies and investors are intensively carried out in the agro-industrial complex [3].

Many business companies offer digital products for the agro-industrial complex:

- Swiss company EcoRobotix has developed a robot for weed weeding;

- German engineering company RobertBosch together with Denmark Agrointelli develops robotic systems for watering and spraying.

Large companies also offer digital solutions for the agricultural market:

- JohnDeere has equipment automation projects;

- Agco has Xavier autonomous robots for sowing, care and harvesting;

- Syngenta has a whole range of digital technologies, among which robots and software products for agriculture stand out [4].

Russia occupies one of the leading places in sown area, efficiency and productivity of agricultural production. Thus, in 2018, in the Russian Federation 4,212 thousand people (about 6\% of the employed throughout the economy) were employed in agriculture and forestry, hunting and fish farming. Russia takes the 3rd place in the world in the area of cultivated land (Figure 1). 


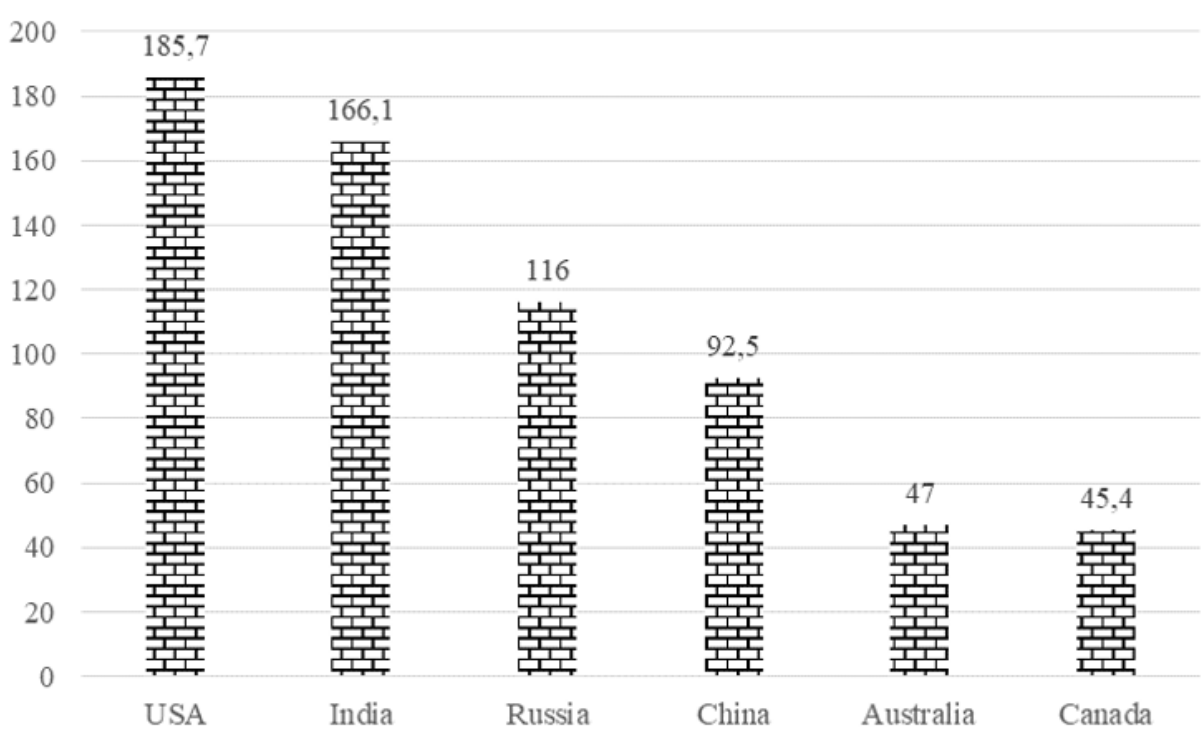

Fig. 1. The largest countries in the world in terms of area of arable land, million hectares.

According to the Federal State Statistics Service and foreign sources, the gross cost of products of the leading agricultural producing countries has the following volumes (Figure 2).

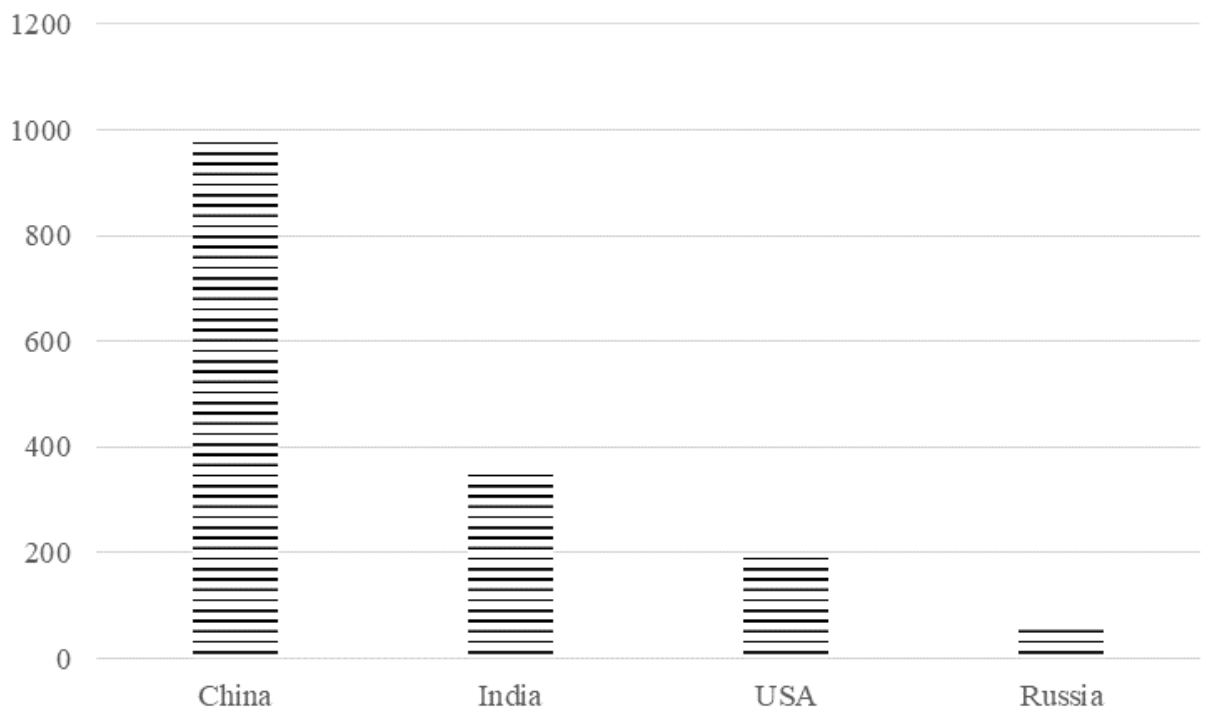

Fig. 2. Gross value of agricultural commodity producers, billion dollars.

Various digital technologies already help to optimize the costs of Russian agricultural producers.

Agricultural machinery with fuel level sensors, cruise control, autopilot, remote monitoring systems, autopilot systems and artificial vision technology already exists today.

During the season the agricultural producer has to make more than 40 different decisions: what seeds to plant, when to plant, how to process them, how to treat a diseased 
plant, etc. The lack of information for decision making leads to the fact that up to $25-40 \%$ of the crop is lost in the process of planting, growing, crops caring. Today $2 / 3$ of the loss factors can be controlled by using automated control systems (Figure 3 ).

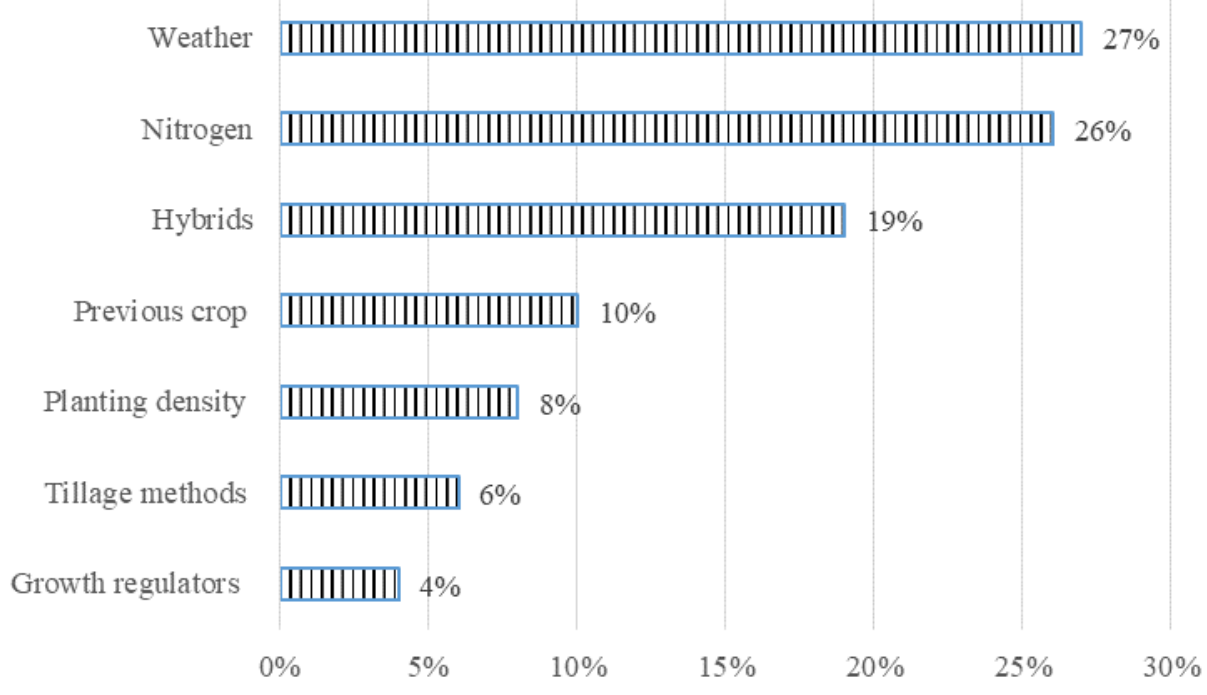

Fig. 3. Factors affecting crop yields, $\%$.

The following digital technologies are most in demand:

- monitoring the condition of crops;

- monitoring and forecasting productivity;

- identification of diseases, detection of pests;

- soil monitoring;

- software platforms for farm management.

As part of the Farm to Consumer program”, blockchain helps companies to track all supply stages of agricultural products and get full access to the entire process of agricultural production. The Netherlands Waterwatch cooperative together with SAP has developed the Crop Disease Alert application, which monitors the process and the conditions of growth and maintenance of plants. If various deviations from the norm are detected, this system notifies the agricultural producer of the various risks to which the plants are exposed at this particular moment and in these specific weather conditions. This software allows agricultural producers to reduce the cost of unnecessary pesticides by more than $15 \%$. Waterwatch cooperative estimates that by the end of 2019, about 1 million agricultural producers in the world will use this software product [5].

Work on one platform allows large agricultural producers to reduce the cost of resources, and not large ones get access to high-quality and inexpensive resources, as well as to optimal distribution channels of manufactured products.

Despite the taken measures the size of ICT costs in the "Agriculture" section, according to the Federal State Statistics Service is 0.85 billion rubles or $0.2 \%$ of all ICT investments in all sectors of the economy in 2018 (Figure 4). It indicates a low digitalization of domestic agricultural production. Increase in investment will increase the level of digitalization of agriculture, its effectiveness. 


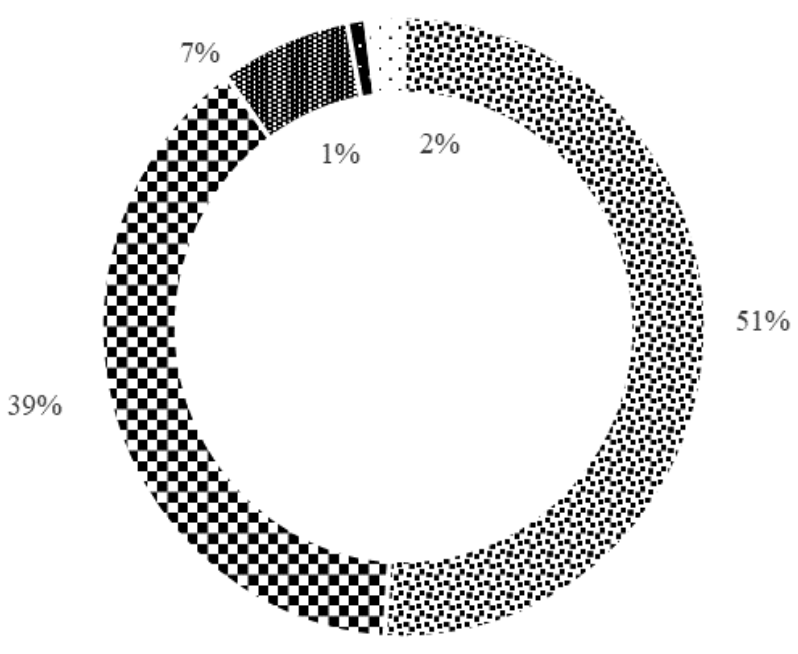

- Plant growing - Food production $\mathbf{x}$ Supporting activities - Animal husbandry · Mixed farming

Fig. 4. Investments in information, computer and telecommunication (ICT) equipment in the Russian Federation.

The constraints of the introduction of digital technologies in Russia include:

- lack of qualified personnel;

- insufficient development of rural digital infrastructure;

- lack of financial resources for the implementation of ICT in most agricultural producers.

This necessitates the development of mechanisms for state support of the agro-industrial complex. The dynamics of the volumes of financial state support in Russia is presented in Figure 5.

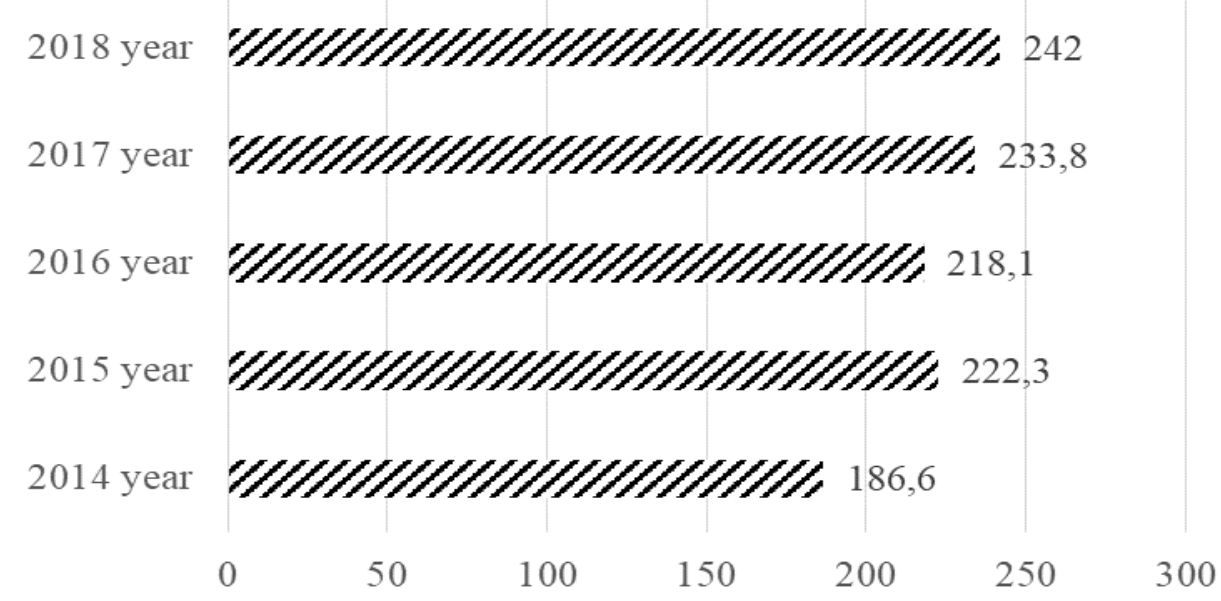

Fig. 5. Dynamics of the state support volume for the agricultural sector in Russia, billion rubles.

Through the state support mechanisms of the agro-industrial complex the amount of funds for the purchase of agricultural machinery is increased 3 times, the industry is being re-equipped, and at the same time, savings on purchased and delivered equipment leads to 
the fact that it does not meet the requirements of the Internet of things management. Besides, the problem of import substitution of agricultural machinery is also acute.

Despite these difficulties, the interest in new technologies in agriculture and the number of regions using them in Russian agriculture is growing, and the number of regions using elements of precision farming is growing. Regions using new technologies in Russia are presented in Figure 6.

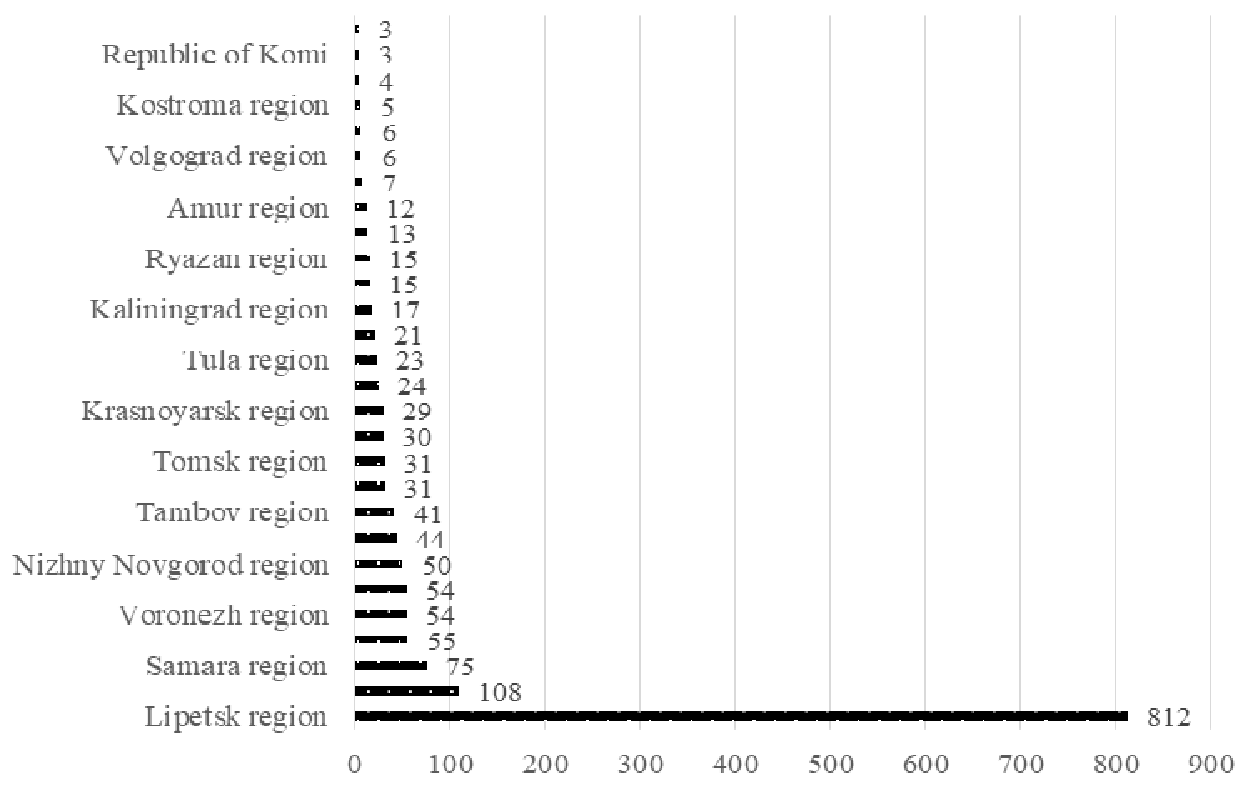

Fig. 6. Rating of regions using precision farming (by number of farms).

Existing digital technologies have long and firmly entered the life of world farmers, but their implementation is uneven. For example, robotic automatic harvesting technologies are used in Spain. Digital technologies related to livestock are developing in Korea. The essence of "smart animal husbandry" is the use of biocompatible sensors that collect accurate and reliable information about the physiological state of each individual animal temperature, $\mathrm{pH}$, and other parameters [6].

The market of modern digital technologies for the agricultural sector is now changing rapidly, and telecom operators are actively involved in this process. Thus, MegaFon offers modern technologies, which include a sensor system for equipment, fields and even animals. The generalization of this information will allow agricultural enterprises to reach a new higher level due to more efficient use of fertilizers and land cultivation, maximum plant protection from pests and diseases, and monitoring livestock health based on real relevant indicators [7]. The increased demand for Internet technologies and digitalization of society as a whole predetermined the transition of MegaFon from a standard telecom operator to an IT leader in digital transformations. MegaFon focused on BigData and the Internet of things. BigData is an effective way to minimize the dependence of crop production on weather and climate conditions [8]. This product offers to take into account when evaluating various factors, such as weather and climate, the intensity and frequency of processing and fertilizing the soil, and others. This technology will minimize the impact of the human factor and allow the introduction of GPS monitoring, digital platforms for the sale and purchase of goods, digital platforms that automatically control agricultural producers based on big data, artificial intelligence and the Internet of things. 
The AIC has always been considered an area where the introduction of new is hard, but everything has changed since the advent of the Internet of Things, as pointed in the study Digitalization in Agriculture, which presented J'son \& Partners Consulting at the end of 2017.

In general, by the end of 2010, there were about two dozen high-tech companies operating in the agricultural sector in the world, and investments in the agricultural sector were $\$ 400$ thousand. There were already more than 1.3 thousand new technological business projects by the end of 2016, the growth rate today makes up 500 high-tech projects per year. Investment in AIC 4.0 at the global level amounted to $\$ 4.6$ billion [9].

\section{Discussion}

The degree of introduction of advanced digital technologies in agricultural production today remains low. Over the past 20 years, software has been introduced for agricultural producers by various companies. There is a big gap between the technologies that are presented at conferences and symposia, and those that are actually being introduced and used in the agricultural sector.

Among the Russian companies working on introduction of digitalization in agriculture, can be highlighted Agronout, which has developed a mechanism for the differential application of fertilizers. This technology enables agricultural machines to change the criteria for their use during operation.

They include doses of fertilizers that are precisely selected for this particular land plot. The agricultural producer makes the distribution of the field plots according to fertility coefficients, and technology calculates the fertilizer application rate for any land plots. The technological process can be used on any land plot, and the economic effect of introduction of this technology will potentially save about 330 million rubles a year per 100 thousand ha. According to the forecasts of the representatives of the agricultural holding "Kuban", in which a pilot project of differential fertilizer application was implemented, it will be 50 million rubles. per year on an area of 45.7 thousand ha. [10]

Russian factories produce smoked sausages using robots. The first robotic plant of the Cherkizovo group uses this process, and only 150 workers are employed in the production compared to 700 before using the technology. The company will be able to provide $30 \%$ of Russia's demand in smoked sausages. The commissioning of such a plant showed the viability of single-product production, therefore, it is planned to commission similar plants in the country that will specialize in the production of cooked, boiled-smoked sausages, sausages, and slices. Such technologies are already actively used in Europe and around world, but for Russia this is the first experience. [11]

It is difficult to make assessments on the percentage of technology penetration into Russian farms. Some elements of smart animal husbandry and precision farming have been implemented in $10 \%$ of agricultural enterprises.

Today, Russia occupies the 15 th place in the world in the implementation of digital technologies in the agro-industrial sector of the economy. Russia is actively developing various programs aimed at the intensive introduction of innovative technologies in the agricultural sector of the economy; a situational center has been created and a digitalization roadmap has been developed. [12]

Among the problems in the implementation of IT technologies, the following can be distinguished: IT product development is determined by demand in the labor market, and it is not cheap. IT developers work in foreign markets, so the cost of such specialists is dictated by the overseas market.

According to a survey of the Monitoring Center, 33\% of the heads of agricultural organizations in Russia restrain new digital technologies because of large financial 
investments, the other part does not have knowledge about the benefits of digitalization, $15 \%$ distrust the new technologies and modern technology, $9 \%$ worry about the time consumption on the development of these technologies and the costs of retraining personnel; $8 \%$ doubt compatibility with their equipment.

Among the main problems of IT technologies introduction in the agro-industrial sector, respondents point out the lack of government programs in the Russian Federation promoting IT technologies. Another $25 \%$ believe that there are no digital advanced technologies in the domestic industry. $22 \%$ of the respondents believe that for the effective implementation of digital technologies there are no local specialists who are able to use this equipment and technologies in the most profitable way; $11 \%$ stop the significant costs of introducing technologies; another $10 \%$ believe that the manufacturers themselves are not interested enough in introduction of such technologies. [13]

The digital platform should be based on a single bus, on an already tested software package for products distribution and bargaining, a program for communication with banking systems, and also a subplatform for interaction between agricultural producers and the state that is currently being developed. All the other components necessary for the implementation of an efficient production process will be connected to the software digital platform, and the other applications on a commercial basis. The introduction of the Digital Platform will create a completely new model of the economic behavior of agricultural producers and give them additional income, many times exceeding all state support for the agricultural sector.

\section{Conclusions}

Taking into account the level of modern technological development of domestic agriculture, the expected effect of the introduction of digital IT technologies and solutions in Russia is significantly higher. Even at the stage of introducing new technologies, agricultural enterprises will be able to save up to $25 \%$ due to techniques and methods that are not directly related to the introduction of digital technologies. These processes include the optimization and standardization of production processes, improvement of the professional training of personnel in the agricultural sector, the introduction of a lean production system, effective models for procurement and inventory management, and optimization of logistics routes. Measures to monitor equipment, reduction downtime and fuel costs can also be included. [14.15]

Agro-industrial enterprises must carry out comprehensive automation and digitalization of production processes, because if you get rid of labor it will not lead to a significant effect and will not make production efficient. [16]

It is necessary to implement a systematic approach to creating integrated systems in order to:

- support new business models and processes for individual market players;

- create an integrated network of farmers, enterprises engaged in the production of agricultural machinery, fertilizer producers, agronomists and logistics operators.

The industry transition to digitalization of business processes will take a lot of time, as old-fashioned peasant farms are relatively competitive, primarily due to cheap labor. At the same time, it is necessary to ensure an acceptable level of Internet and IT technologies penetration into Russian villages, as required by the integration of AIC in modern competitive conditions. 


\section{References}

1. R. Bukht, R. Heeks, Global Development Institute working papers 68 (2017) https://diodeweb.fi les. wordpress.com/

2. Decree of the President of the Russian Federation "The national goals and strategic objectives of the Russian Federation for the period up to 2024", http://kremlin.ru/ events/president/news/57425 2

3. L.A. Alexandrova, E.V. Lapteva, E.P. Ogorodnikova, Digital transformation of the Russian economy, features and ways of development. Expert of year (2019)

4. S. Rotz, E. Gravely, I. Mosby, E. Duncan, E. Fraser, Journal of Rural Studies 68, $112-$ 122 (2019)

5. K. Rijswijk, L. Klerkx, J.A. Turner, NJAS - Wageningen Journal of Life Sciences 9091, 100313 (2019)

6. P.W.B. Phillips, J.-A. Relf-Eckstein, G. Jobe, B. Wixted, NJAS - Wageningen Journal of Life Sciences 90-91, 100295 (2019)

7. M. Anshari, M. Nabil Almunawar, M. Masri, M. Hamdan, Energy Procedia 156, 234238 (2019)

8. T. Hovhannisyan, P. Efendyan, M. Vardanyan, Annals of Agrarian Science 16(2), $177-$ 180 (2018)

9. M. Carmela Annosi, F. Brunetta, A. Monti, F. Nati, Computers in Industry 109, 59-71 (2019)

10. Wen Dong, Tianjun Wu, Jiancheng Luo, Yingwei Sun, Liegang Xia, Geoderma 340, 234-248 (2019)

11. J.L. Drewry, J.M. Shutske, D. Trechter, B.D. Luck, L. Pitman, Computers and Electronics in Agriculture 165, 104960 (2019)

12. M. Zeraatpisheh, E. Bakhshandeh, M. Hosseini, S. Mohammad, Alavi Geoderma 3631, 114139 (2020)

13. M.L. Vartanova, Journal of Russian Entrepreneurship 19(6), 1803-1824 (2018)

14. M.L. Vartanova, Social policy and sociology 16- 3(122), 20-28 (2017)

15. E. Faham, H. Asghari, Computers and Electronics in Agriculture 165, 104935 (2019) 